18,12

\title{
Ab initio моделирование влияния расположения и свойств упорядоченных вакансий на магнитное состояние монослоя графена
}

\author{
(C) М.М. Асадов ${ }^{1}$, С.Н. Мустафраева ${ }^{2}$, С.С. Гусейнова ${ }^{2}$, В.Ф. Лукичев ${ }^{3}$, Д.Б. Тагиев ${ }^{1}$ \\ ${ }^{1}$ Институт катализа и неорганической химии им. М.Ф. Нагиева НАНА, \\ Баку, Азербайджан \\ ${ }^{2}$ Институт ффизики НАНА, \\ Баку, Азербайджан \\ ${ }^{3}$ Физико-технологический институт им. К.А. Валиева РАН, \\ Москва, Россия \\ E-mail: mirasadov@gmail.com
}

Поступила в Редакцию 23 декабря 2020 г.

В окончательной редакции 3 января 2021 г.

Принята к публикации 15 января 2021 г.

Ab initio-методом псевдопотенциала в рамках DFT моделированы свойства гексагонального графена с учетом влияния вакансий, связанных с ближнеупорядоченной структурой. Рассчитаны магнитные свойства суперьячеек графена с 18, 54 и 96 атомами углерода с моно- и дивакансиями. Внесения вакансий углерода на монослой графена вызывает появление локального магнитного момента. Численные оценки величины магнитного момента выполнены для суперъячеек графена с 18, 54 и 96 атомами углерода с вакансиями. Получены значения магнитных моментов и определена область локализации спиновой плотности в суперъячейке с 96 атомами углерода, включающей как ближнерасположенные, так и дальнерасположенные вакансии. Изучено влияние расстояния между вакансиями на величину магнитного момента в суперъячейке графена. Исследованы зависимости магнитного момента и расстояния между вакансиями в суперъячейке графена с 96 атомами от концентрации вакансий. С помощью расчетов энергии образования вакансий углерода в суперъячейке графена изучены ее зависимости от деформации ячейки графена.

Ключевые слова: ab initio-расчет, теория функционала плотности, суперъячейки графена, вакансии, магнитный момент, спиновая плотность, расположение вакансий, энергия образования и концентрация вакансий, деформация ячейки графена.

DOI: 10.21883/FTT.2021.05.50822.268

\section{1. Введение}

Квантовые 2D-материалы привлекают внимание исследователей из-за уникальных физических свойств и возможностей их применения в микро- и наноустройствах [1]. Изучение внутреннего магнетизма в таких материалах позволяет понимать электронный механизм и важно для разработки устройств спинтроники [2]. Различные типы 2D-материалов обладают различными спин-зависимыми свойствами: например, графен обеспечивает спиновый транспорт [3].

Процессы формирования магнитных моментов (M) в графене можно разделить на два способа: а) создание точечных дефектов на плоскости графена, в частности, путем введения других атомов или функциональных групп в углеродные сетки графена [4-7]; и б) создание дефектов в краевых узлах структуры графена, например, путем введения вакансий $[8,9]$.

Магнетизм, вызванный дефектами в структуре графена, стабилен в широком диапазоне концентраций дефектов [10]. Магнитные свойства графеновых систем зависят от их электронной структуры [11], в частности, от влияния вакансий [12]. Локальные магнитные момен- ты оказывают влияние также и на другие физические свойства графена [13-21].

Влияние индуцированных вакансиями магнитных моментов на электрические свойства графена изучено в [22] с помощью измерений магнитотранспорта и расчетов теории функционала плотности со спиновой поляризацией. В расчетах использован пакет моделирования Vienna ab initio. C помощью измерений Холла в графене с вакансиями показано, что локальные магнитные моменты, индуцируются вакансиями в графене. Связь между локализованным состоянием и переносимым носителем зависит от изменения концентрации носителей, температуры, магнитного поля и плотности вакансий. Такая связь приводит к модулированному магнитотранспорту за счет перехода от отрицательного к положительному магнитосопротивлению. Плотности состояний (density of states, DOS) „чистого“ графена и графена с одной углеродной вакансией отличаются. C учетом ab initio расчетных данных DOS и электронных зонных структур графена и измерений Холла показано, что заполненные электроны ниже уровня Ферми $\left(E_{\mathrm{F}}\right)$ дают локальный магнитный момент $2 \mu_{\mathrm{B}}$.

В литературе масса информации и работ по изучению влияния точечных дефектов [23-25] и деформации на 
свойства графена [26,27]. Важно также изучение зависимости его свойств от магнитного состояния и от расстояния между дефектами.

Сравнение магнитных [22], электронных [23], термодинамических и деформационных [24-30] характеристик графена при различных температурах с аналогичными характеристиками графена с учетом вакансий показало отличие изучаемых величин на порядок.

В настоящей работе приведены результаты изучения влияния вакансий, связанных с ближнеупорядоченной структурой, на магнитные свойства монослоя графена с вакансиями. Далее коротко рассмотрим суть некоторых работ, посвященных графену с упорядоченными вакансиями с учетом состояния вакансии атома углерода, поляризованной по спину с магнитным моментом.

Результаты DFT-изучения электронной структуры и магнитных свойств вакансий в двумерных графеновых структурах приведены в работе [31]. Используя модель Хаббарда среднего поля изучено появление магнитных состояний, связанных с удалением одиночной вакансии и множества соседних атомных пустот, а также магнитные взаимодействия между ними. Показано, что атомная структура графена связана с пространственным расположением вакансий и возникающим магнитным порядком. Полный спин $S$ данного точечного дефекта зависит от дисбаланса его подрешетки, но некоторые вакансии с $S=0$ могут иметь локальные магнитные моменты. Несбалансированность подрешеток также определяет, взаимодействуют ли вакансии друг с другом ферромагнитно или антиферромагнитно. Отмечено, что в двумерном графене без глобального дисбаланса подрешеток существует максимальная плотность вакансий, выше которой исчезает локальная намагниченность. При достаточном расстоянии друг от друга две вакансии с локальным дисбалансом ведут себя как два независимых объекта с локальным спином $2 S$. Ниже определенного расстояния они уничтожают друг друга, а локальная намагниченность обращается в нуль. Когда две вакансии объединяются, то в результате формируется область с повышенной локальной намагниченностью и спином $2 S$. Спиновые взаимодействия между двумя магнитнымы вакансиями могут быть трех типов: ферромагнитные и антиферромагнитные или аннигилирующие. В первом случае спин основного состояния представляет собой сумму спинов, созданных магнитными дефектами, когда они бесконечно разнесены. Во втором случае спин это разница между этими двумя состояниями. В третьем случае и полные и локальные спины равны нулю. Антиферромагнитная и аннигилирующая связи возникают в решетках без глобального дисбаланса подрешеток, тогда как для ферромагнитной связи требуется глобальный дисбаланс подрешеток.

Спин-поляризованной теорией функционала плотности в работе [32] изучено влияние вакансионных дефектов на магнитные свойства графена. Оптимизацией структуры показано, что введение кластера углеродной вакансии в лист графена изменяет пространственное распределение соседних атомов, особенно расположенных вокруг вакансии. На основе расчетов спин-поляризованных DOS и LPDOS обнаружено, что только вакансии, содержащие неспаренные $2 p$-электроны C, проявляют магнетизм. Показано, что между магнитным моментом, индуцированным вакансией, размером и формой кластеров вакансий в листе графена имеется связь. Т.е. магнетизм в графене, обусловленный вакансиями, сильно зависит от расположения, размера и формы вакансионных дефектов. Для вакансионных конфигураций, в которых отсутствует нечетное количество атомов C, сохраняется по крайней мере одна оборванная связь. Таким образом, в графене с вакансией присутствуют локальные магнитные моменты, демонстрирующие ферромагнитную связь между атомами C на вакансионных дефектах.

В работе [33] также указано, что вакансии в графене приводят к появлению локализованных электронных состояний с ненулевыми спиновыми моментами. Исследовано влияние деформации на локализацию и магнитные свойства вакансионных состояний в нанолентах типа „кресло“. Показано, что спин-обменное расщепление одиночной вакансии и синглет-триплетное расщепление двух вакансий можно регулировать, применяя одноосную деформацию, которая имеет значение для приложений спинтроники.

Результаты DF-расчетов структурных параметров, электронных и магнитных свойств системы G-h-BN, coдержащей нанолисты графена $(\mathrm{G})$ с вакансиями, приведены в работе [34]. Показано, что образование вакансии является эндотермическим процессом и три разных типа моновакансий образуются на разных участках гибридной структуры GBN. Две различные моновакансии C, моновакансия B и $\mathrm{N}$ образовались на границе раздела G/h-BN. Дополнительно были сформированы моновакансия С в области $\mathrm{G}$ и моновакансии В и $\mathrm{N}$ в области h-BN гибридного нанолиста. Изучены возможные влияния вакансий и размерных эффектов гексагонального островка $\mathrm{G}$ на электронные и магнитные свойства гибрида GBN. Pacчетные энергии образования вакансий показывают, что вакансия N имеет более низкую энергию образования, чем вакансия В. В зависимости от типа вакансии и вакансионного узла гибрид GBN может стать магнитным со значительным магнитным моментом. Моновакансии вводят плоские (бездисперсионные) состояния вблизи уровня Ферми, и эти энергетические состояния приводят к локализованному целочисленному магнитному моменту. Вакансионный дефект индуцирует небольшой магнитный момент в гибриде GBN с островком h-BN. Моновакансия уменьшает ширину запрещенной зоны исходного гибрида. В частности, моновакансия индуцирует целочисленный магнитный момент в гибриде GBN. Целочисленный магнитный момент возникает из-за оборванных связей атомов вблизи вакансии. Независимо от типа вакансии и расположения вакансии гибриды с островками h-BN становятся металлическими и понижают уровень Ферми. В целом корреляции между размером 
гексагонального островка графена G и магнитным моментом дефектного гибрида GBN не наблюдались.

На основе метода сильной связи в [35] исследована функция Грина для материалов с ячеистой кристаллической решеткой, содержащих вакансии. Рассмотрены известные и часто используемые модели описания вакансий и аналитически продемонстрирована их эквивалентность. Также было показано, что вклады в плотность квазичастичных состояний от обеих подрешеток ячеистой решетки одинаковы, за исключением нулевой энергии, независимо от того, в какой из подрешеток находится вакансия.

Влияние сдвиговых искажений на индуцированный вакансиями магнетизм в графене в [36] исследовано с помощью расчетов из первых принципов. Обнаружено, что сдвиговые искажения могут приводить к магнитному переходу между двумя состояниями с высоким и низким магнитными моментами. Такой переход является обратимым и является результатом нарушения симметрии в плоскости локальных атомов, который меняет спиновую поляризацию $\pi$-зон вакансионных состояний вблизи уровня Ферми и приводит к изменению магнитного перехода на $1 \mu_{\mathrm{B}}$.

В работе [37] приведены результаты расчетов из первых принципов свойств вакансии в графите. Показано, что за счет вакансии происходит искажение структуры, что приводит к ослаблению и реконструированнию связи $\mathrm{C}-\mathrm{C}(2.1 \pm 0.1 \AA)$. А это в свою очередь приводит к небольшим смещениям атомов вне плоскости. Эта последняя особенность искажения увеличивает взаимодействие вакансии с другими дефектами, что в свою очередь, влияет на ее энергию миграции и электронное поведение. Расчетная энергия миграции $1.7 \mathrm{eV}$ ниже, чем известная из экспериментов. Авторы предполагают, что расхождение объясняется измененной картиной захвата во время переноса вакансий в зависимости от концентрации.

Используя теорию спин-поляризованного функционала плотности в [38] исследованы свойства моновакансии в листе графена. Приведенное основное состояние вакансии, поляризованной по спину с магнитным моментом $1.04 \mu_{\mathrm{B}}$, относится к расположению $\mathrm{C}-\mathrm{C}$ атомов вокруг вакансии в суперъячейке со 128 атомами углерода. Показано, что энергия образования такого графенового листа с вакансией из 128 атомов сходилась с точностью до $0.02 \mathrm{eV}$ по отношению к размеру графенового листа. Атомы 1 и 2 образуют протяженную связь $\mathrm{C}-\mathrm{C}$ длиной $2.02 \AA$ по сравнению со стандартной длиной $1.42 \AA$ для графена. Плотность заряда вокруг вакансии демонстрирует увеличение плотности между атомами 1 и 2, что указывает на образование слабой ковалентной связи.

Электронная структура графена с вакансией изучена в [39], комбинацией подходов на основе теории функционала плотности, сильной связи и функции Грина. Исследования функционала плотности выполнены с помощью метода спин-поляризованных линейных дополненных

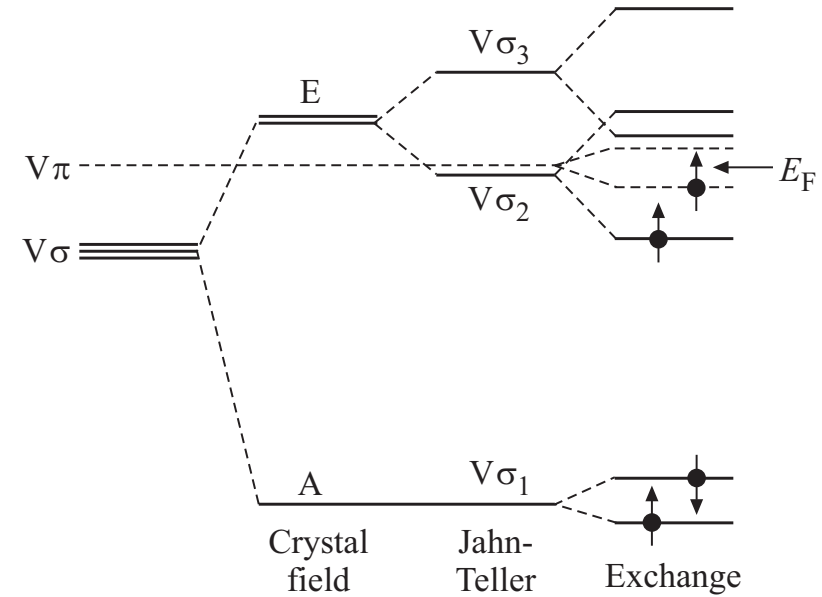

Рис. 1. Схема расщепления трех локализованных состояний оборванной связи $s p^{2} \sigma$ углеродного треугольника, обозначенного $\mathrm{V} \sigma$, и индуцированного вакансией нулевого состояния $\mathrm{V} \pi$, происходящего из зоны $\pi[39]$.

плоских волн (LAPW). Показано, что три оборванные связи $s p^{2} \sigma$, примыкающие к вакансии, вводят локализованные состояния $(\mathrm{V} \sigma)$ в области средней щели зонной структуры, которая расщепляется из-за кристаллического поля и ян-теллеровского искажения. Что касается магнитного момента вакансии, связь по правилу Хунда выравнивает спины четырех локализованных электронов $\mathrm{V} \sigma 1 \uparrow \downarrow, \mathrm{V} \sigma 2 \uparrow$ и $\mathrm{V} \pi \uparrow$, что приводит к состоянию $S=1$ с магнитным моментом $2 \mu_{\mathrm{B}}$, который уменьшается на $0.3 \mu_{\mathrm{B}}$ из-за антиферромагнитной спиновой поляризации локализованных $\pi$ электронов в окрестности вакансии. Это приводит к магнитному моменту $1.7 \mu_{\mathrm{B}}$. Формирование состояния $\mathrm{V} \pi$ исследовано с помощью приближения функции Грина для изолированной вакансии. Обсуждается возможное расщепление трех состояний оборванной связи $s p^{2} \sigma$ углеродного треугольника, обозначенного $\mathrm{V} \sigma$, и индуцированного вакансией нулевого состояния $\mathrm{V} \pi$, происходящего из зоны $\pi$. Результаты DFT-расчетов представлены, в частности схематически, на рис. 1. Согласно этой схеме локализованное состояние $\mathrm{V} \sigma$ расщепляется на состояния $\mathrm{V} \sigma_{1}, V \sigma_{2}$ и $\mathrm{V} \sigma_{3}$ из-за искажения кристаллического поля (1) и искажения ЯнаТеллера (2), а также за счет обменного взаимодействия между элктронами (3).

Влияние вакансионных дефектов на электронные и фононные свойства графена исследовано с помощью моделей, основанных на элементарной ячейке из 180 атомов углерода и 1, 2, 3, 6 и 24 вакансий [40]. Стабильность упорядоченных с одним дефектом на элементарную ячейку и неупорядоченных (случайно расположенных) вакансий рассчитана с помощью методов ab initio и молекулярной динамики. Показано, что случайно ориентированные вакансии приводят к созданию характерных дефектов и аморфизации графена. Проанализированы электронные и фононные плотности состояний. Переключение электропроводности с метал- 
лического на полупроводниковый тип наблюдается при увеличении размеров дефекта от одиночной вакансии до больших кластеров.

В работе [41] предложена модель, включающая использование возможности квантового отжига для решения проблем, связанных с оценкой относительной стабильности графеновых вакансионных дефектов. Путем сопоставления взаимодействий, доминирующих в обмене углеродных вакансий, для оптимизации используется как основное состояние, так и возбужденные состояния атомов, обнаруженные квантовым отжигателем. Таким путем с учетом статистических свойств квантового отжига оцениваются возможные конфигурации множественных дефектов на листе графена вместе с их относительными энергиями образования. Это позволяет упрощать сравнение энергии между конфигурациями графеновой системы и получить доступ ко всем равноэнергетическим конфигурациям многомерного пространства.

Анализ вышеуказанных работ по формированию магнетизма за счет того, что на атомах углерода ближайшего окружения вакансии индуцируются локальные магнитные моменты, приводит к следующему заключению. В этих работах не рассматривается влияние вакансий на магнитные свойства графена с учетом расстояния между вакансиями и их концентрации.

\section{2. Методика расчета}

Атомная орбиталь, как известно из квантовой химии, - это функция, которая описывает плотность электронного облака в каждой точке пространства вокруг ядра данного атома. На втором энергетическом уровне атома углерода, например, четыре орбитали $-2 s, 2 p_{x}$, $2 p_{y}, 2 p_{z}$. Эти орбитали различаются: а) формой электронного облака ( $s$ - шар, $p$ - гантель); б) p-орбитали имеют разную ориентацию в пространстве - вдоль взаимно перпендикулярных осей $x, y$ и $z$, их обозначают $p_{x}, p_{y}, p_{z}$. Так как в графене рассматривали гибридные орбитали, то они отличаются от исходных (негибридных) орбиталей формой и энергией. Например, $s$-орбиталь - форма сферы, $p$ - симметричная восьмерка, $s p^{2}$-гибридная орбиталь - асимметричная восьмерка. Различия по энергии $E(s)<E(s p)<E(p)$ указывают на то, что $s p^{2}$-орбиталь - усредненная по форме и энергии орбиталь, полученная смешиванием исходных $s$ - и $p$-орбиталей.

В состоянии $s p^{2}$-гибридизации одна орбиталь симметрична и три асимметричные. Размеры орбиталей являются зависимыми переменными. Если принимать, что ориентация одной из орбиталей (например, ось $z$ ) основная, то в сферической системе координат можно представить ориентации трех остальных орбиталей шестью переменными.

При образовании вакансий в состоянии $s p^{2}$-гибридизации углеродных атомов взаимное пространственное расположение указанных четырех орбиталей и их размеры должны меняться. Т.е. разное взаимное пространственное расположение четырех орбиталей и их размеры приводят к различию в гибридизированных состояниях. При этом внесенные, в частности, в графен углеродные вакансии могут влиять на степень гибридизации и на изменение распределения электронной плотности в пространстве вокруг углеродных ядер с вакансиями в сравнении с распределением электронной плотности в образующих данную связь углеродных атомов

$\mathrm{Ab}$ initio методом расчета изучали свойства гексагонального графена с моно- и дивакансиями (SV и DV). Использовали спин-поляризованную теорию функционала плотности (density functional theory, DFT [42]) в градиентном приближении. Расчеты проводили потенциальным способом в программном пакете Atomistix Tool Kit (ATK). Применяли обобщенное градиентное приближение в виде функционала Пердь-Берка-Эрнцерхофа (PBE functional)-Generalized Gradient Approximation (GGA) [43,20,21].

В точке рассмотрения энергии суперъячейки графена при использовании метода GGA учитывается спин электрона и градиент плотности

$$
E_{\mathrm{XC}}^{\mathrm{GGA}}\left[n_{\uparrow}, n_{\downarrow}\right]=\varepsilon_{\mathrm{XC}}^{\mathrm{GGA}}\left(n_{\uparrow}, n_{\downarrow}, \nabla n_{\uparrow}, \nabla n_{\downarrow}\right) n(r) d^{3} r
$$

где $\varepsilon_{\mathrm{XC}}^{\mathrm{GGA}}$ - обменно-корреляционная энергия суперъячейки, имеющей постоянную плотность $n(r)$ в зависимости от межслоевого расстояния $d$.

DFT-GGA-способ расчета электронных свойств гексагонального графена обеспечивает использование периодического набора инструментов АТК. При этом получается высокая точность расчета полной энергии при минимальном количестве подгоночных параметров [44]. Расчет магнитных моментов графена проводили анализом заселенности по Малликену. Заданные $k$-точки в зоне Бриллюэна использовали для оптимизации геометрических параметров и сетки, что обеспечивает точность расчета энергии системы. Для интегрирования в обратном пространстве и вычисления электронной плотности использованы четыре $k$-точки в первой зоне Бриллюэна.

Оптимизацию геометрических координат всех атомов в суперьячейке варьировали с учетом сопряженных градиентов путем вычисления сил, действующих на атомы. Оптимизацию геометрии проводили путем минимизации сил, действующих на каждый атом. Таким образом кристаллическую ячейку графена расслабляли и геометрически оптимизировали с допуском к силе $0.001 \mathrm{eV} / \AA$ и напряжению $0.001 \mathrm{eV} / \AA^{3}$. Кинетическая энергия отсечки в расчетах составляла $150 \mathrm{Ry}$. Расчеты проводили для трех суперьячеек с числом атомов углерода 18, 54 и 96, содержащих вакансии.

Свойства неэквивалентных магнитных конфигураций графена вычисляли с учетом моно- и дивакансий. Каноническую статистическую сумму $\left(S_{c}\right)$ вычисляли по разности полной энергии $n$-й конфигурации графеновой 
системы и энергии этой системы в основном состоянии:

$$
S_{c}=\sum_{n=1}^{5} \exp \left(-\left(E_{n}-E_{0}\right) /\left(k_{\mathrm{B}} T\right)\right),
$$

где $E_{n}$ - полная энергия системы в $n$-м энергетическом состоянии, $E_{0}-$ энергия основного состояния, $k_{\mathrm{B}}-$ постоянная Больцмана, $T=1400 \mathrm{~K}$ (средняя температура существования графена).

Вероятность существования магнитного состояния в графене вычисляли по отношению вклада виртуального точечного дефекта (вакансии) $S_{n}$ в статистическую сумму $\left(S_{c}\right): P_{N}=S_{n} / S_{c}$. Таким образом вычисляли среднее по магнитным моментам (M) значение полной энергии суперъячейки графена, содержащей одну или две вакансии: $\langle E\rangle=\Sigma_{n} E_{n} P_{n}$.

В суперъячейках, содержащих как моно-, так и дивакансии изучали зависимости энергии образования вакансий от деформации (сжатия-растяжения) графена [24-28]. Использовали двумерную суперъячейку в плоскости, которая имела квадратный вид. Такая форма суперьячейки строится из периодически связанных прямоугольных элементарных ячеек графена. Это позволяет уменьшить влияние формы ячейки на деформацию, а также построить зависимость свойств монослоя графена от расстояния между дефектами. Степень деформации кристаллической решетки графена моделировали с учетом компонентов тензора в направлениях осей $x$ и $y$. Относительно начального состояния суперъячейку деформиовали по коодинатам $x$ и $y$ на $-2.5 \%$ и $2.5 \%$ соответственно.

\section{3. Результаты и обсуждение}

Суперьячейки графена с 18, 54 и 96 атомами углерода состоят из периодически повторяющихся сердцевин. Суперъячейки с малым количеством атомов позволяют оптимизировать работу программного обеспечения и выполнять точные теоретические расчеты. При использовании DFT в суперьячейках взаимодействием между атомами можно пренебречь.

На атомах углерода ближайшего окружения вакансии $\mathrm{V}_{\mathrm{C}}$ индуцируются локальные магнитные моменты (M), величина которых, в частности, может быть связана с деформацией кристаллической решетки благодаря влиянию основного синглетного состояния (где, в системе из двух частиц, суммарный спин которых равен 0) неспаренного электрона атома углерода, аналогично работе [45].

В суперьячейки графена вносили как ближне-, так и дальнерасположенные вакансии атомов углерода. Возникновение химической связи между некоторыми атомами углерода в графене с вакансией приводит к локализации электронных состояний углерода вблизи уровня Ферми. Обменное взаимодействие между этими локализованными состояниями индуцирует появление
Таблица 1. Сравнение DFT расчетных значений магнитных моментов $\left(\mathrm{M}, \mu_{\mathrm{B}}\right)$ в суперъячейке графена с литературными данными

\begin{tabular}{l|c}
\hline \multicolumn{2}{c}{$\mathrm{M}, \mu_{\mathrm{B}}$} \\
\hline 1.15 & $1.5,1.7,2[22]$ \\
1.33 & $1.04[38]$ \\
1.4 & $1.12-1.5[10]$ \\
1.99 & $2[46]$ \\
& $1.7-2[39]$
\end{tabular}

магнетизма в графеновом слое. Магнитный момент на атоме углерода согласно [46] имеет значение $2 \mu_{\mathrm{B}}$.

Анализом заселенности по Малликену расчитаны локальные магнитные моменты суперъячеек графена с 18, 54 и 96 атомами, которые составляли 1.15, 1.33, $1.99 \mu_{\text {В }}$ соответственно. Сравнение этих магнитных моментов с литературными данными $[10,22,38,39,46]$, полученными также расчетным путем, показало их хорошое соответствие (табл. 1)

Сравнение результатов наших расчетов $\mathrm{M}\left(\mu_{\mathrm{B}}\right)$ суперъячеек графена с 18, 54 и 96 атомами углерода, содержащих вакансии, и литературных данных показали, что в последних отсутствуют наборы данных, достоверно описывающие магнитные характеристики. Основные различия проявляются в описании размера и конфигурации суперьячеек графена, зависимости локального магнитного состояния от расстояния между центрами углеродных атомов и вакансиями, влиянии количества вакансий, а магнитные моменты воспроизводятся в целом хорошо.

В качестве примера рассмотрим суперьячейку графена с 96 атомами, где ближне расположенные атомы углерода, „извлечены“ из монослоя графена (рис. 2). Суперъячейка с 96 атомами углерода, включающая ближне расположенные вакансии, например, $\mathrm{V}_{\mathrm{C}} 35$ и $\mathrm{V}_{\mathrm{C}} 39$, приобретает больший магнитный момент $\left(1.99 \mu_{\mathrm{B}}\right)$ по сравнению с дальне расположенными вакансиями ато-

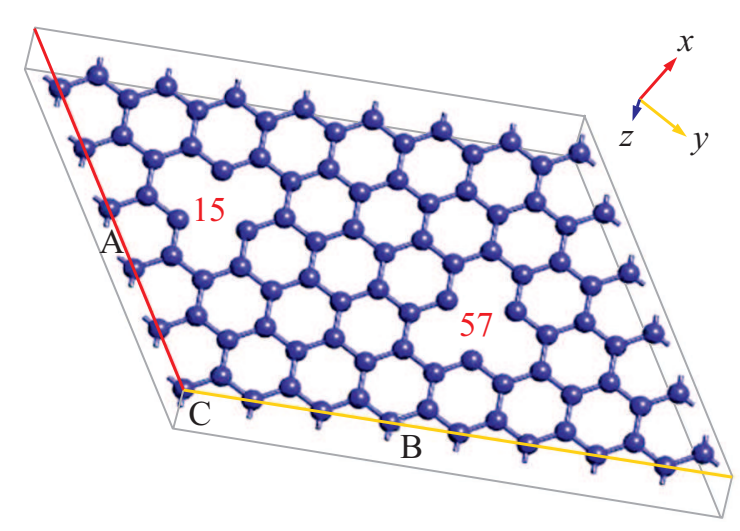

Рис. 2. Схема суперьячейки графена с 96 атомами углерода с упорядоченными вакансиями по координатным осям $x, y, z$ (вакансии -15 и 57 атомы углерода). 
мов, например, $\mathrm{V}_{\mathrm{C}} 15$ и $\mathrm{V}_{\mathrm{C}} 57\left(1.15 \mu_{\mathrm{B}}\right)$, а также $\mathrm{V}_{\mathrm{C}} 36$ и $\mathrm{V}_{\mathrm{C}} 52\left(1.33 \mu_{\mathrm{B}}\right)$. В суперьячейке графена изучена область локализации спиновой плотности $\left(\rho_{S}\right): \rho_{S}=\rho_{S \uparrow}-\rho_{S \downarrow}$, где $\rho_{S \uparrow}$ и $\rho_{S \downarrow}-$ плотность распределения электронов со спином вверх $(+1 / 2 \hbar)$ и со спином вниз $(-1 / 2 \hbar)$ соответственно.

Суперьячейка графена с 96 атомами углерода, содержащая вакансии, по данным расчета DFT приобретает два состояния с магнитными моментами $1.99 \mu_{\mathrm{B}}$ и $1.4 \mu_{\mathrm{B}}$. Эти значения М соответствуют высокоспиновому и низкоспиновому состояниям суперьячейки графена, соответственно. Последнее состояние атома энергетически выгоднее по сравнению с высокоспиновым состоянием на $\sim 0.02 \mathrm{eV}$.

В суперъячейке графена с 96 атомами и вакансией углерода спиновая плотность $\rho_{S}$ локализована на атомах углерода, окружающих вакансию. В низкоспиновом состоянии $\rho_{S}$ распределяется следующим образом. Спины электронов на двух из трех атомов углерода вблизи вакансии направлены вверх, а на одном атоме - вниз.

Спин-поляризованный расчет свойств указывает на магнитное состояние в графене, включающем вакансию. При начальной заселенности электронов принимали, что проекции спинов имеют одинаковое направление в суперъячейке. Спиновая плотность распределяется равномерно на атомах углерода, окружающих вакансию. Влияние расстояния между вакансиями $\left(r_{V_{\mathrm{C}}}\right)$ на магнитное состояние суперьячеек графена с 18, 54 и 96 атомами углерода заметное.

Так например, увеличение $r_{\mathrm{V}_{\mathrm{C}}}$ от 7 до $12 \AA$ приводит к переходу от антиферромагнитного (AFM) к ферромагнитному (FM) упорядочению. При указанных $r_{\mathrm{V}_{\mathrm{C}}}$ разница энергий между FM- и AFM-состояниями составляет от 0.006 до $-0.01 \mathrm{eV}$. Другими словами с увеличением расстояния между вакансиями $r_{\mathrm{V}_{\mathrm{C}}}$ углерода вероятность ферромагнитного состояния в суперьячейках графена увеличивается.

Исследовали ферромагнитное, антиферромагнитное и немагнитное состояния в суперъячейках графена. Ферромагнитное состояние получается автоматически при спин-поляризованном расчете. FM-состояние характеризует начальное заселение системы электронами с одинаково направленными проекциями спина. Это соответствует низкоспиновому состоянию, которое является энергетически выгодным [19].

Антиферромагнитное состояние задавали посредством чередования локальных магнитных моментов на атомах, окружающих вакансию в суперьячейке графена с 96 атомами углерода. Магнитные моменты атомов графена, окружающих вакансии, близко расположенные друг к другу, упорядочивали таким образом, чтобы они были направлены противоположно магнитным моментам атомов, окружающих вакансии, далеко стоящие друг от друга.

Для монослоев суперьячеек графена с 18 и 54 атомами углерода также применяли аналогичное упорядочение. Для каждой из этих суперъячеек рассчитыва- ли немагнитное состояние, где суммарный магнитный момент равен нулю. При этом для этих суперьячеек графена без учета магнитного взаимодействия рассчитанное состояние является энергетически не выгодным. Таким образом, физическая причина $\mathrm{FM} \rightarrow \mathrm{AFM}$-перехода связана с изменением знака обменного интеграла при спин-поляризованном расчете. При сравнении это проявляется в разнице по энергии между выгодным из магнитоупорядоченных состояний (ферро- либо антиферро-) и немагнитным состоянием.

Такая магнитная связь между локальными магнитными моментами очень слабая, что связано с небольшой разницей в энергии между различными конфигурациями спина [47]. Пространственное распределение спиновой плотности отображает особенности ферромагнитного выравнивания для наиболее стабильной конфигурации. Отметим, что физическое явление, определяющее механизм возникновения ферромагнетизма в углеродных структурах, является сложным и пока до конца не выясненным $[48,49]$. На рис. 3 приведены зависимости концентрационного распределения магнитного момента и расстояния между вакансиями в суперъячейке графена с 96 атомами. Увеличение концентрации вакансий приводит к уменьшению расстояния между ними и линейному росту величины магнтного момента.

Зависимость магнитного момента от расстояния между вакансиями $r_{\mathrm{V}_{\mathrm{C}}}$ в графене с 96 атомами углерода, включающем вакансии, приведена на рис. 4. Магнитный момент увеличивается с уменьшением расстояния между вакансиями в графене с 96 атомами, причем при значениях $r_{\mathrm{V}_{\mathrm{C}}}$, меньших $10 \AA$, этот рост становится круче.

Незначительный излом на рассчетных кривых рис. 3 и 4, видимо, не несет физического смысла. Такой излом, по-видимому, связан с применением высокочувствительного программного продукта с визуальным отображением значений $r_{\mathrm{V}_{\mathrm{C}}}$ и $\mathrm{M}\left(\mu_{\mathrm{B}}\right)$ в суперъячейке монослоя

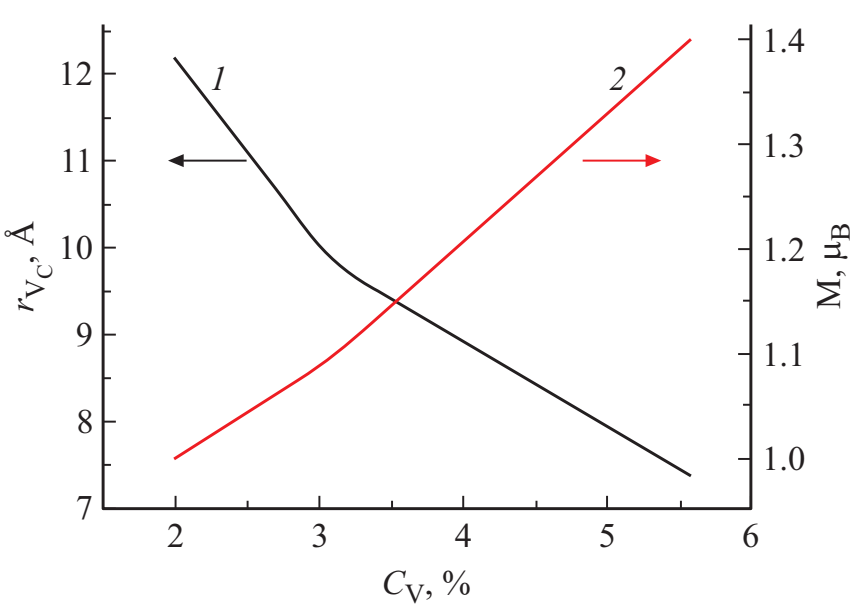

Рис. 3. Концентрационные зависимости расстояния между вакансиями (кривая 1) и магнитного момента (кривая 2) в суперъячейке монослоя графена с 96 атомами, содержащей вакансии. 


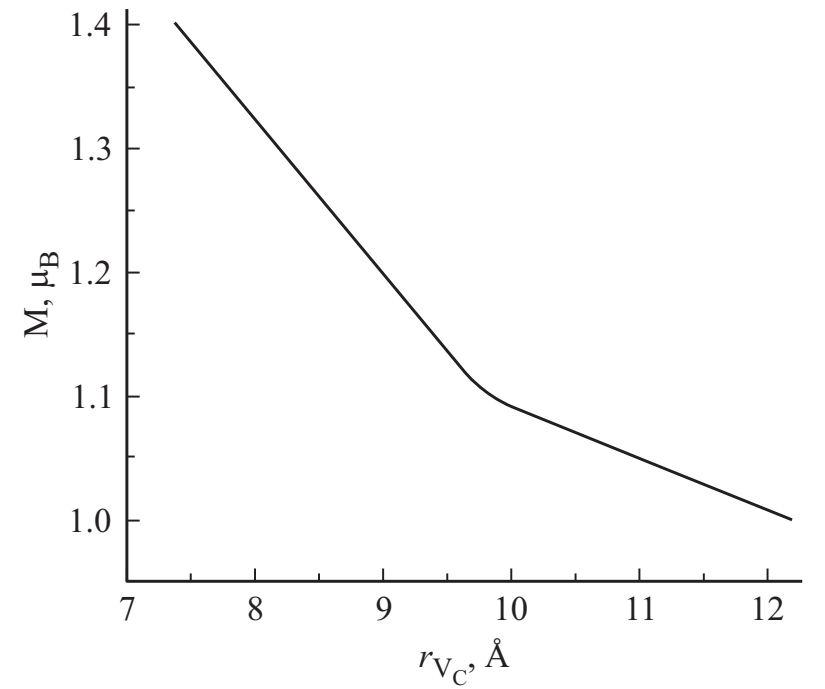

Рис. 4. Зависимость магнитного момента от расстояния между вакансиями $r_{\mathrm{V}_{\mathrm{C}}}$ в суперъячейке монослоя графена с 96 атомами углерода, включающем вакансии.

графена с 96 атомами и автоматическим установлением вида рассчетных кривых.

Энергию образования моно- и дивакансий по углероду С в графене (gp) вычисляли по формуам

$$
\begin{gathered}
E_{f}\left(S \mathrm{~V}_{\mathrm{C}}\right)=E_{\mathrm{tot}}^{\mathrm{V}}\left(S \mathrm{~V}_{\mathrm{C}}\right)-E_{\mathrm{tot}}^{\mathrm{gp}}+\mu_{\mathrm{C}}, \\
E_{f}\left(S V_{\mathrm{C}}\right)=E_{\mathrm{tot}}^{\mathrm{V}}\left(D \mathrm{~V}_{\mathrm{C}_{1} \mathrm{C}_{2}}\right)-E_{\mathrm{tot}}^{\mathrm{gp}}+\mu_{\mathrm{C}_{1}}+\mu_{\mathrm{C}_{2}} .
\end{gathered}
$$

где $E_{f}\left(S V_{\mathrm{C}}\right)$ - энергия образования моновакансий по углероду $\mathrm{V}_{\mathrm{C}}, E_{\mathrm{tot}}^{\mathrm{V}}\left(D \mathrm{~V}_{\mathrm{C}_{1} \mathrm{C}_{2}}\right)$ и $E_{\mathrm{tot}}^{\mathrm{gp}}-$ полная энергия графена с дивакансией и без вакансий, $\mu_{\mathrm{C}}-$ химический потенциал (энергия) наиболее стабильной модификации атомов углерода (графита) $\mathrm{C}-[\mathrm{He}] 2 s^{2} 2 p^{2}$. Химический потенциал соответствующего атома углерода $i$, удаленного при создании вакансии $\mu_{\mathrm{C}_{i}}$, определяли как

$$
\mu_{\mathrm{C}_{i}}=E_{\mathrm{tot}}^{\mathrm{gp}}-\left(E_{\mathrm{V}_{\mathrm{C}}}^{\text {u.c. }} / 2\right)
$$

где $E_{\mathrm{tot}}^{\mathrm{gr}}-$ полная энергия элементарной ячейки графена, $E_{\mathrm{V}_{\mathrm{C}}}^{\text {u.c. }}-$ энергия элементарной ячейки для стабильной фазы углерода с вакансией.

Исходя из данных DFT-PBE для энергии образования моно- и дивакансий получили 7.3 и $7.2 \mathrm{eV}$ соответственно. Эти вычисленные нами энергии образования монои дивакансий по углероду в графене согласуются с известными данными (табл. 2).

Исследовали влияние одноосной деформации $(\varepsilon)$ кристаллической решетки графена на энергию образования вакансий атомов углерода. В расчетном блоке для моделирования свойств кристалла графена, содержащем 96 атомов, создавали моно- и дивакансии. Построены зависимости энергии образования вакансии атомов углерода от деформации решетки графена.

В стартовой конфигурации расчетного блока деформацию задавали путем изменения межатомных расстояний
Таблица 2. Сравнение DFT-PBE расчетных значений энергии образования вакансий в суперъячейке графена с литературными данными

\begin{tabular}{c|c}
\hline \multicolumn{2}{c}{$E_{f}^{\mathrm{V}_{\mathrm{C}}}, \mathrm{eV}$} \\
\hline$S \mathrm{~V}_{\mathrm{C}}$ & $D \mathrm{~V}_{\mathrm{C}}$ \\
\hline 7.3 & 7.2 \\
$7.3-7.5[37]$ & $7.2-7.9[50,37]$ \\
$7.5[51]$ & $7.47[51]$
\end{tabular}

поперек оси $C$ графена (перпендикулярное направление в гексагональном кристалле графена). Как для идеального кристалла, так и для кристалла, содержащащего вакансии, деформацию рассматривали от $-2.5 \%$ (сжатие) до $2.5 \%$ (растяжение). Близкий диапазон значений, например, для металлов (от -3 до $3 \%$ ) соответствует пластической деформации.

Вакансии вызывают изменение в электронной структуре графена и деформируют его кристаллическую решетку. Относительная деформация элементарной кристаллической ячейки, в частности, зависит от энергии образования дефектов и концентрации этих точечных дефектов. Влияние значения $\varepsilon$ решетки на стабильность монослоя графена с вакансией моделировали путем изменения длины вектора трансляции в направлениях осей $x$ и $y$.

Деформация почти не оказывает влияния на энергии образования вакансий $E_{f}^{\mathrm{V}_{\mathrm{C}}}$ атома углерода при сжатии $(-2.5 \%)$ кристаллической решетки графена с вакансиями. Малое снижение энергии образования вакансий происходит только при растяжении до $2.5 \%$ графена.

Для графена с моно- и дивакансией энергия образования вакансий при растяжении уменьшается. Потенциалы взаимодействия вакансий с атомами С не отличаются заметным энергетическим изменением. На рис. 5 при-

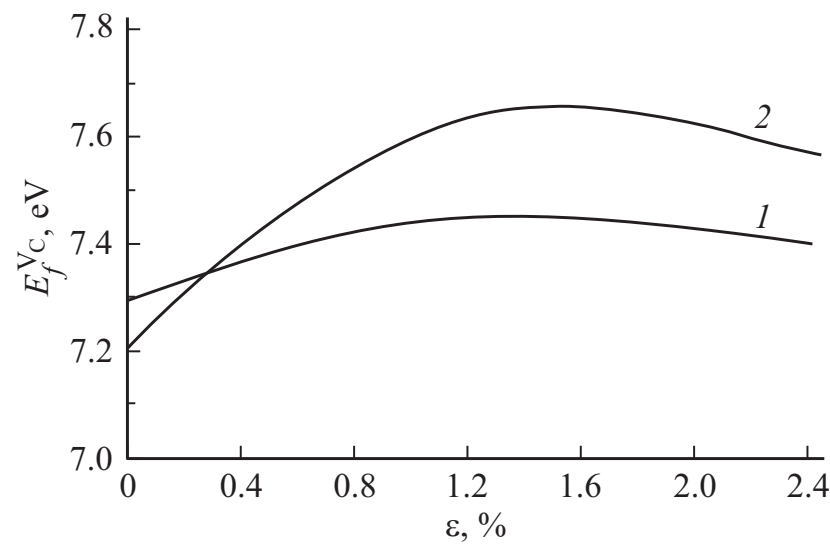

Рис. 5. Зависимость энергии образования вакансии углерода в суперъячейке графена с 96 атомами от одноосной деформации кристаллической решетки. 1 - графен с моновакансией; 2 - графен с дивакансией при растяжении перпендикулярно направлению вакансии. 
ведены зависимости $E_{f}^{\mathrm{V}_{\mathrm{C}}}$ от деформации кристаллической решетки графена при растяжении перпендикулярно направлению вакансии. Из вычисленных зависимостей $E_{f}^{\mathrm{V}_{\mathrm{C}}}=f(\varepsilon)$ следует, что деформация оказывает слабое влияние на энергию образования моновакансий. Т. е. при деформации решетки графена сравнительно стабильным является графен с моновакансией (кривая 1).

С повышением деформации стабильность кристаллической решетки графена с дивакансией увеличивается (кривая 2). Видно, что при растяжении графена энергия образования дивакансий атомов С монотонно снижается. Таким образом, сравнение кривых 1 и 2 (рис. 5) для графена с моновакансией и графена с дивакансией указывает на то, что деформация решетки мало влияет на характер схожих зависимостей $E_{f}^{\mathrm{V}_{\mathrm{C}}}=f(\varepsilon)$.

Влияние деформации на энергию образования дивакансий в графене более выражено, чем зависимость $E_{f}^{\mathrm{V}_{\mathrm{C}}}=f(\varepsilon)$ с участием моновакансии. Несмотря на высокие значения энергии связи атомов графена [52], при деформации поверхности графена с дивакансиями связи атомов $\mathrm{C}-\mathrm{C}$ могут ослабляться (или разрываться) под действием $s p^{2}$-гибридизации атомов углерода.

Т.е. при деформации возможно происходит ослабление ковалентных связей атомов $\mathrm{C}-\mathrm{C}$ в суперьячейке графена с дивакансиями. За счет этого с повышением деформации монотонно уменьшается и $E_{f}^{\mathrm{V}_{\mathrm{C}}}$ в графене. Кроме того уменьшение $E_{f}^{\mathrm{V}_{\mathrm{C}}}$ при упругом растяжении можно связать также с увеличением доли свободного объема суперъячейки графена с дивакансиями по сравнению с суперьячейкой графена с моновакансией.

Число вакансий углерода в графене определили по формуле: $n_{\mathrm{V}_{\mathrm{C}}}^{\mathrm{gp}}=\exp \left(-E_{f}^{\mathrm{V}_{\mathrm{C}}} k_{\mathrm{B}} T\right)$, где $n_{\mathrm{V}_{\mathrm{C}}}^{\mathrm{gp}}-$ число вакансий в монослое графена; $E_{f}^{\mathrm{V}_{\mathrm{C}}}-$ энергия образования вакансии углерода в монослое графена; $T$ температура. Если кристалл графена состоит из $N$ атомов углерода, то в отсутствии упругой деформации отношение равновесного числа вакансий $n_{\mathrm{V}_{\mathrm{C}}}^{\mathrm{gp}}$ к числу занятых атомами мест $\left(N-n_{\mathrm{V}_{\mathrm{C}}}^{\mathrm{gp}}\right)$ при $N \gg n_{\mathrm{V}_{\mathrm{C}}}^{\mathrm{gp}}$ равно концентрации вакансий $\mathrm{V}_{C}$, определяемой соотношением: $C_{\mathrm{V}}=n_{\mathrm{V}_{\mathrm{C}}}^{\mathrm{gp}} / N=\exp \left(-E_{f}^{\mathrm{V}_{\mathrm{C}}} / k_{\mathrm{B}} T\right)$. Здесь $E_{f}^{\mathrm{V}_{\mathrm{C}}}>0$, концентрация вакансий экспоненциально увеличивается при повышении температуры. С учетом этих данных оцененная концентрация вакансий при $T=298 \mathrm{~K}$ незначительная.

\section{4. Заключение}

По данным ab initio-вычислений методом псевдопотенциала в рамках DFT обнаружено, что внесение вакансий углерода на монослои гексагонального графена, вызывает появление локального магнитного момента. Магнитные моменты суперьячеек графена с 18, 54 и 96 атомами углерода, содержащих вакансии, согласно анализу заселенности по Малликену составляли 1.15 , $1.33,1.99 \mu_{\mathrm{B}}$ соответственно. Полученные в настоящей работе результаты находятся в удовлетворительном согласии с литературными. С помощью расчетов DFT установлено, что в суперьячейке с 96 атомами углерода, включающей вакансии, в различных расположениях вакансий величины магнитных моментов различны. Ближне расположенные вакансии углерода $\mathrm{V}_{\mathrm{C}}$, например, $\mathrm{V}_{\mathrm{C}} 35$ (атом углерода) и $\mathrm{V}_{\mathrm{C}} 39$ (атом углерода), приобретают большой магнитный момент $\left(1.99 \mu_{\mathrm{B}}\right)$, по сравнению с дальне расположенными вакансиями атомов, например, $\mathrm{V}_{\mathrm{C}} 15$ и $\mathrm{V}_{\mathrm{C}} 57\left(1.15 \mu_{\mathrm{B}}\right)$, а также $\mathrm{V}_{\mathrm{C}} 36$ и $\mathrm{V}_{\mathrm{C}} 52\left(1.33 \mu_{\mathrm{B}}\right)$.

Значения магнитных моментов, соответствующие высокоспиновому и низкоспиновому состояниям суперъячейки графена, составляют $1.99 \mu_{\mathrm{B}}$ и $1.4 \mu_{\mathrm{B}}$ соответственно. По сравнению с высокоспиновым состоянием энергия образования низкоспинового состояния меньше на $\sim 0.02 \mathrm{eV}$.

Влияние расстояния между вакансиями $\left(r_{\mathrm{V}_{\mathrm{C}}}\right)$ на магнитное состояние суперьячейки графена с 96 атомами углерода заметное. Увеличение $r_{\mathrm{V}_{\mathrm{C}}}$, например, от 7 до $12 \AA$ приводит к переходу от антиферромагнитного (AFM) к ферромагнитному (FM) упорядочению. При указанных расстояниях $r_{\mathrm{V}_{\mathrm{C}}}$ разница энергий между FMи АFМ-состояниями составляет от 0.006 до $-0.01 \mathrm{eV}$. Во всех рассмотренных суперьячейках графена с 18, 54 и 96 атомами углерода с увеличением расстояния между вакансиями углерода вероятность ферромагнитного состояния графена увеличивается. А с уменьшением расстояния между вакансиями в графене, в частности, с 96 атомами магнитный момент увеличивается.

Вычисленные концентрационные зависимости расстояния между вакансиями и магнитного момента, а также зависимости энергии образования вакансий углерода от деформации кристаллической ячейки графена с 96 атомами определяют условия направленного движения вакансий или приложенной деформации. Вычисленные энергии образования моно- и дивакансий углерода в графене с вакансиями составили 7.3 и $7.2 \mathrm{eV}$ соответственно. Эти значения энергии находятся в удовлетворительном согласии с литературными.

\section{Благодарности}

Работа выполнена при частичной поддержке Фонда развития науки при Президенте Азербайджанской Республики (грант № E IF-BGM-3-BRFTF-2+/2017-15/05/1M-13) и Российского фонда фундаментальных исследований (проект № Az_a2018).

\section{Конфликт интересов}

Авторы заявляют, что у них нет конфликта интересов.

\section{Список литературы}

[1] K.S. Burch, D. Mandrus, J.G. Park. Nature 563, 7729, 47 (2018). https://doi.org/10.1038/s41586-018-0631-z

[2] Li Hui, R. Shuangchen, Z. Yu Jia. Adv. Mater. 31, 27, 1900065 (2019). https://doi.org/10.1002/adma.201900065 
[3] A. Avsar, H. Ochoa, F. Guinea, B. Ozyilmaz, B.J. van Wees, I.J. Vera-Marun. Appl. Phys. Rev. Mod. Phys. 92, 21003 (2020). https://doi.org/10.1103/RevModPhys.92.021003

[4] T. Tang, N.J. Tang, Y.P. Zheng, X.G. Wan, Y. Liu, F.C. Liu, Q.H. Xu, Y.W. Du. Sci. Rep. 5, 8448 (2015). https://doi.org/10.1038/srep08448

[5] L. Xie, X. Wang, J. Lu, Z. Ni, Z. Luo, H. Mao, R. Wang, Y. Wang, H. Huang, D. Qi, Rong Liu, T. Yu, Z. Shen, T. Wu, H. Peng, B. Özyilmaz, K. Loh, T.S. Andrew, C.W. Ariando. Appl. Phys. Lett. 98, 19, 193113 (2011). https://doi.org/10.1063/1.3589970

[6] T. Tang, F.C. Liu, Y. Liu, X.Y. Li, Q.H. Xu, Q. Feng, N.J. Tang, Y.W. Du. Appl. Phys. Lett. 104, 12, 123104 (2014). https://doi.org/10.1063/1.4869827

[7] J. Chen, W.L. Zhang, Y.Y. Sun, Y.P. Zheng, N.J. Tang, Y.W. Du. Sci. Rep. 6, 26862 (2016). https://doi.org/10.1038/srep26862

[8] R.R. Nair, M. Sepioni, I.L. Tsai, O. Lehtinen, J. Keinonen, A.V. Krasheninnikov, T. Thomson, A.K. Geim, I.V. Grigorieva. Nature Phys. 8, 199 (2012). https://doi.org/10.1038/NPHYS2183

[9] A. Ney, P. Papakonstantinou, A. Kumar, N.-G. Shang, N. Peng. Appl. Phys. Lett. 99, 102504 (2011). https://doi.org/10.1063/1.3628245

[10] O.V. Yazyev, L. Helm. J. Phys. Conf. Ser. 61, 1 (2007). https://doi.org/10.1088/1742-6596/61/1/255

[11] E. Kan, Z. Li, J. Yang. Nano 3, 6, 433 (2008). https://doi.org/10.1142/s1793292008001350

[12] B. Uchoa, V.N. Kotov, N.M.R. Peres, A.H. Castro. Phys. Rev. Lett. 101, 026805 (2008). https://doi.org/10.1103/PhysRevLett.101.026805

[13] J.-H. Chen, W.G. Cullen, E.D. Williams, M.S. Fuhrer. Nature Phys. 7, 535 (2011). https://doi.org/10.1038/NPHYS1962

[14] X. Hong, S.H. Cheng, C. Herding, J. Zhu. Phys. Rev. B 83, 8, 085410 (2011). https://doi.org/10.1103/physrevb.83.085410

[15] Y.-B. Zhou, B.-H. Han, Z.-M. Liao, H.-C. Wu, D.-P. Yu. Appl. Phys. Lett. 98, 222502 (2011). https://doi.org/10.1063/1.3595681

[16] J. Moser, H. Tao, S. Roche, F. Alzina, C.M. Sotomayor Torres, A. Bachtold. Phys. Rev. B 81, 20, 205445 (2010). https://doi.org/10.1103/PhysRevB.81.205445

[17] B.R. Matis, F.A. Bulat, A.L. Friedman, B.H. Houston, J.W. Baldwin. Phys. Rev. B 85, 195437 (2012). https://doi.org/10.1103/PhysRevB.85.195437

[18] X. Hong, K. Zou, B. Wang, S.-H. Cheng, J. Zhu. Phys. Rev. Lett. 108, 226602 (2012). https://doi.org/10.1103/PhysRevLett.108.226602

[19] K.M. McCreary, A.G. Swartz, W. Han, J. Fabian, E.K. Kawakami. Phys. Rev. Lett. 109, 18, 186604 (2012). https://doi.org/10.1103/physrevlett.109.186604

[20] М.М. Асадов, С.С. Гусейнова, В.Ф. Лукичев. Микроэлектроника 49, 5, 334 (2020).

https://doi.org/10.31857/S0544126920050038. [M.M. Asadov, S.S. Guseinova, V.F. Lukichev. Rus. Microelectron. 49, 5, 314 (2020). https://doi.org/10.1134/S106373972005003021]

[21] М.М. Асадов, С.Н. Мустафаева, С.С. Гусейнова, В.Ф. Лукичев. ФТТ 62, 11, 1929 (2020). [M.M. Asadov, S.N. Mustafaeva, S.S. Guseinova, V.F. Lukichev. Phys. Solid State 62, 11, 2224 (2020)]. https://doi.org/10.1134/S1063783420110037]

[22] J.-J. Chen, H-C. Wu, D.-P. Yu, Z.-M. Liao. Nanoscale 6, 15, 8814 (2014). https://doi.org/10.1039/c3nr06892g
[23] V. Skrypnyk. Low Temper. Phys. 44, 11, 1417 (2018). https://doi.org/10.1063/1.5060964

[24] А.А. Кузубов, М.В. Сержантова, А.С. Федоров, Ф.Н. Томилин, Т.А. Кожевникова, Письма в ЖЭТФ 93, 6, 368 (2011). [A.A. Kuzubov, M.V. Serzhantova, A.S. Fedorov, F.N. Tomilin, T.A. Kozhevnikova. JETP Lett. 93, 6, 335 (2011). https://doi.org/10.1134/s0021364011060051].

[25] А.А. Кузубов, Ю.Е. Ананьева, А.С. Федоров, Ф. Томилин, П. Краснов. Журн. физ. химии 86, 7, 1204 (2012). [A.A. Kuzubova, Yu.E. Anan'eva, A.S. Fedorova, F.N. Tomilina, P.O. Krasnov. Rus. J. Phys. Chem. A 86, 7, 1088 (2012). https://doi.org/10.1134/S0036024412070126].

[26] А.С. Федоров, Д.А. Федоров, З.И. Попов, Ю.Е. Ананьева, Н.С. Елисеева, А.А. Кузубов. ЖЭТФ 139, 5, 938 (2011). [A.S. Fedorov, D.A. Fedorov, Z.I. Popov, Yu.E. Anan'eva, N.S. Eliseeva, A.A. Kuzubov. J. Exp. Theor. Phys. 139, 5, 820 (2011). https://doi.org/10.1134/S1063776111040042].

[27] Ю.А. Баимова, С.В. Дмитриев, А.В. Савин, Ю.С. Кившарь. ФTT 54, 4, 813 (2012). [Yu.A. Baimova, S.V. Dmitriev, A.V. Savin, Yu.S. Kivshar'. Phyis. Solid State 54, 4, 866 (2012). https://doi.org/10.1134/s1063783412040026]

[28] V.T. Barone, B.R. Tuttlea. AIP Adv. 10, 105115 (2020). https://doi.org/10.1063/5.0018703

[29] Н.С. Елисеева, А.А. Кузубов, С.Г. Овчинников, М.В. Сержантова, Ф.Н. Томилин, А.С. Федоров. Письма в ЖЭТФ 95, 11, 633 (2012). [N.S. Eliseeva, A.A. Kuzubov, S.G. Ovchinnikov, M.V. Serzhantova, F.N. Tomilin, A.S. Fedorov. JETP Lett. 95, 11, 555 (2012). https://doi.org/10.1134/s0021364012110045].

[30] K.V. Zakharchenko, A. Fasolino, J.H. Los, M.I. Katsnelson. J. Phys.: Condens. Matter. 23, 20, 202202 (2011). https://doi.org/10.1088/0953-8984/23/20/202202

[31] J.J. Palacios, J. Fernández-Rossier, L. Brey. Phys. Rev. B 77, 19, 195428 (2008).

https://doi.org/10.1103/PhysRevB.77.195428

[32] X.Q. Dai, J.H. Zhao, M.H. Xie, Y.N. Tang, Y.H. Li, B. Zhao. Phys. J. B 80, 3, 343 (2011).

https://doi.org/10.1140/epjb/e2011-10955-x

[33] D. Midtvedt, A. Croy. Condens. Matter. 28, 4, 045302 (2016). https://doi.org/10.1088/0953-8984/28/4/045302

[34] N. Akman, C. Ozdogan. J. Magn. Magn. Mater. 502, 166530 (2020). https://doi.org/10.1016/j.jmmm.2020.166530

[35] Y.V. Skrypnyk, V.M. Loktev. Low Temp. Phys. 42, 8, 679 (2016). https://doi.org/10.1063/1.4961016

[36] F. Gao, S. Gao. Sci. Rep. 7, 1, 1792 (2017). https://doi.org/10.1038/s41598-017-01881-3.

[37] A.A. El-Barbary, R.H. Telling, C.P. Ewels, M.I. Heggie. Phys. Rev. B 68, 14, 144107 (2003). https://doi.org/10.1103/physrevb.68.144107

[38] Yuchen Ma, P.O. Lehtinen, A.S. Foster, R.M. Nieminen. New J. Phys. 6, 68, 1 (2004). https://doi.org/10.1088/13672630/6/1/068

[39] B.R.K. Nanda, M. Sherafati, Z.S. Popovic, S. Satpathy. New J. Phys. 14, 083004 (2012). https://doi.org/10.1088/1367-2630/14/8/083004

[40] A.V. Pokropivny, Y. Ni, Y. Chalopin, Y.M. Solonin, S. Volz. Phys. Status Solidi B 251, 3, 555 (2014). https://doi.org/10.1002/pssb.201300301

[41] V. Carnevali, I. Siloi, R. Di Felice, M. Fornari. arXiv:2010.05803v1 [cond-mat.mtrl-sci] 12 Oct. 2020. https://doi.org/10.1039/D0CP04037A 
[42] W. Kohn, L.J. Sham. Phys. Rev. B 140, 4, 1133 (1965). https://doi.org/10.1103/physrev.140.a1133

[43] J.P. Perdew, S. Burke, M. Ernzerhof. Phys. Rev. Lett. 77, 18, 3865 (1996). https://doi.org/10.1103/physrevlett.77.3865

[44] W.A. Koch, M.C. Holthausen. Chemist's guide to density functional theory. 2nd ed. Wiley-VCH Verlag GmbH (2001). 293 p. ISBN: 978-3-527-30372-4

[45] M. Acik, Y.J. Chabal. Jpn. J. Appl. Phys. 50, 7, 070101 (2011). https://doi.org/10.1143/JJAP.50.070101]

[46] A. Ramasubramaniam, N.V. Medhekar, V.B. Shenoy. Nanotechnology 20, 27, 275705 (2009). https://doi.org/10.1088/0957-4484/20/27/275705

[47] X. He, T. He, Z. Wang, M. Zhao. Physica E 42, 9, 2451 (2010). https://doi.org/10.1016/j.physe.2010.06.010

[48] Т.Л. Макарова. ФТП 38, 6, 641 (2004).

[49] Carbon-Based Magnetism: An Overview of Metal Free Carbon-Based Compounds and Materials / Eds T. Makarova, F. Palacio. Elsevier, Amsterdam (2006). ISBN-13: 978-0-444-51947-4

[50] A.V. Krasheninnikov, P.O. Lehtinen, A.S. Foster, R.M. Nieminen. Chem. Phys. Lett. 418, 1-3, 132 (2006). https://doi.org/ 10.1016/j.cplett.2005.10.106

[51] F. Banhart, J. Kotakoski, A.V. Krasheninnikov. ACS Nano 5, 1, 26 (2010). https://doi.org/10.1021/nn102598m

[52] H. Amara, J.-M. Roussel, C. Bichara, J.-P. Gaspard, F. Ducastelle. Phys. Rev. B 79, 014109 (2009). https://doi.org/ 10.1103/physrevb.79.014109

Редактор Т.Н. Василевскал 